\title{
Müllerian duct cyst misdiagnosed as ovarian cyst: a rare case report
}

\author{
Alpana Singh, Sneha Shree*, Vandana Mishra, Gita Radhakrishnan
}

Department of Obstetrics \& Gynecology, Institute of University College of Medical Sciences \& Guru Teg Bahadur Hospital, Delhi, India

Received: 12 February 2016

Revised: 13 February 2016

Accepted: 08 March 2016

*Correspondence:

Dr. Sneha Shree,

E-mail: shreesnehapmc@gmail.com

Copyright: (C) the author(s), publisher and licensee Medip Academy. This is an open-access article distributed under the terms of the Creative Commons Attribution Non-Commercial License, which permits unrestricted non-commercial use, distribution, and reproduction in any medium, provided the original work is properly cited.

\begin{abstract}
The Müllerian duct cyst is a remnant of the caudal ends of the fused embryologic paramesonephric ducts (or Müllerian ducts). Preoperative distinction of ovarian cyst from a Müllerian duct cyst is important and is based on visualization of the ipsilateral ovary separate from the mass. Müllerian duct cysts may also be mistaken as paratubal, paraovarian or peritoneal inclusion cysts and hydrosalpinx. Thus, preoperative diagnosis of Müllerian cyst of the uterus can be very challenging. However, with increased awareness, preoperative diagnosis of this condition should be possible by sonography. Laparoscopy is useful as a minimally invasive treatment to diagnose as well as resect the cyst at the same time. We present a rare case of Müllerian duct cyst misdiagnosed as ovarian cyst pre-operatively and managed laparoscopically. A 32 year old multiparous female presented with the complaint of lump and dull aching pain in lower abdomen since three months. A cystic mobile mass measuring 6 X7 cm with smooth surface which corresponded to 16 weeks gravid uterus size was palpated arising from pelvis. Her pelvic ultrasonography revealed a $7 \mathrm{X} 7 \mathrm{~cm}$ unilocular thin walled simple cyst in right ovary suggestive of serous cystadenoma. Her CA-125 was 5.3 $\mathrm{IU} / \mathrm{ml}$. She was taken up for laparoscopic ovarian cystectomy. Intra-operatively, a $7 \mathrm{X} 7 \mathrm{~cm}$ cyst was seen arising from right lateral wall of uterus. Histopathology showed the cyst wall features consistent with a Müllerian duct cyst.
\end{abstract}

Keywords: Müllerian duct cyst, Ovarian cyst, Laparoscopy, Ultrasonography

\section{INTRODUCTION}

The Müllerian duct cyst is a remnant of the caudal ends of the fused embryologic paramesonephric ducts (or Müllerian ducts). ${ }^{1}$ They are uncommon pelvic cystic lesions, with the peak clinical incidence between the third and fourth decades of life. ${ }^{2}$ Usually they are small and asymptomatic, sometimes they are large, resulting in symptoms such as pelvic pain and pressure symptoms. They are thin walled and unilocular, hence it is difficult to differentiate them from a benign ovarian cyst on imaging. Treatment is indicated in symptomatic individuals only and is aimed at complete excision of the cyst. Both open and minimally invasive approaches have been described, but with pre-operative diagnosis, minimally invasive procedures may suffice in their management.

\section{METHODS}

A 32 year old multiparous female presented to our outpatient department with the complaint of a lump and dull aching pain in lower abdomen for three months. Her menstrual cycles were regular and she had five living issues. Her general physical examination was not remarkable. On abdominal examination, a mass arising from pelvis was palpated which corresponded to 16 weeks gravid uterus size and clinically measured $6 \times 7$ $\mathrm{cm}$. It was cystic in consistency, with smooth surface and horizontal mobility. On bimanual pelvic examination, the 
same cystic mass was felt in right adnexa; however, uterus was not felt separate from the mass. On rectal examination, rectal mucosa and parametria were free of nodularity or induration. Clinical investigations were carried out; the routine blood work-up was normal. Her pelvic ultrasonography revealed a $7 X 7 \mathrm{~cm}$ unilocular thin walled simple cyst in right ovary with normal vascularity which was suggestive of serous cystadenoma. Her CA125 was $5.3 \mathrm{IU} / \mathrm{ml}$. Thus, with the above diagnosis, she was taken up for laparoscopic ovarian cystectomy. Intraoperatively, a $7 \times 7 \mathrm{~cm}$ cyst was seen arising from the right lateral wall of the uterus (Figure 1). Bilateral tubes and ovaries were healthy. Approximately $300 \mathrm{cc}$ of clear cystic fluid was aspirated; cyst wall was removed and sent for histopathology (Figure 2). A frozen section was not carried out as the cyst was uterine in origin at laparoscopy and appeared benign with no clinical evidence of malignancy. Post-operative diagnosis of cystic degeneration of subserosal fibroid was made. Postoperative course was uneventful and the patient was discharged in a stable condition. On histopathological examination, cyst wall was lined with cuboidal epithelium and showed fibrocollagenous tissue interspersed with smooth muscle cells along with congested capillaries and few chronic inflammatory cells; features consistent with a Müllerian duct cyst (Figure 3).

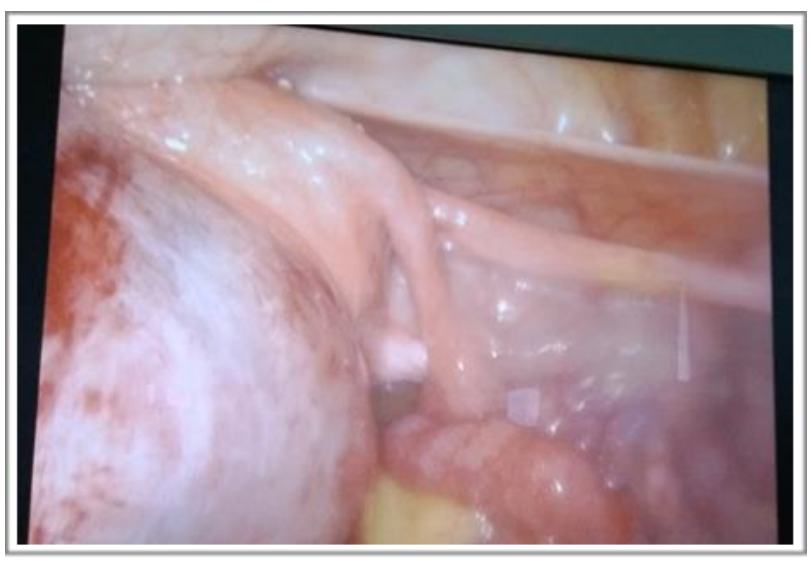

Figure 1: Cyst at posterior surface of uterus.

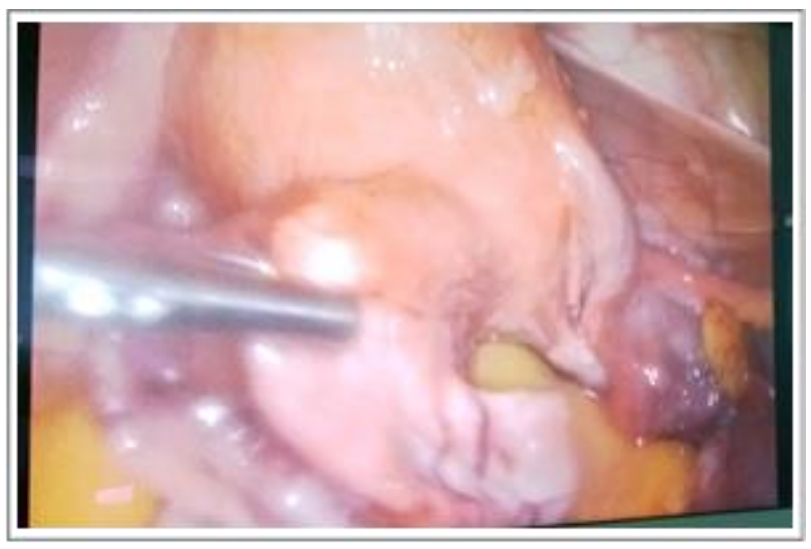

Figure 2: Cyst decompressed prior to removal.

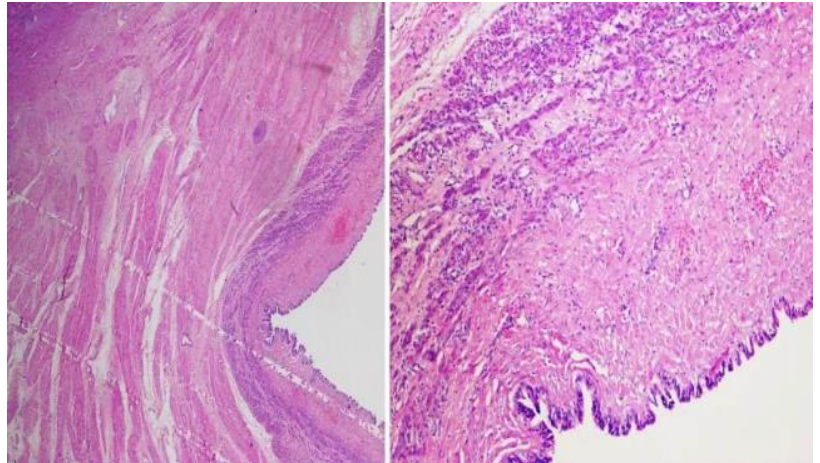

Figure 3: Histopathology of cyst wall showing features consistent with a Müllerian duct cyst.

\section{DISCUSSION}

The Müllerian cyst represents remnants of Müllerian system. A prevalence of $1-5 \%$ has been reported for Müllerian duct cysts, but symptomatic presentation is very rare. ${ }^{3}$ Preoperative distinction of ovarian cyst from a Müllerian duct cyst is important and is based on visualization of the ipsilateral ovary separate from the mass. Though rarely symptomatic, complications due to torsion, internal haemorrhage and rupture massive sizes have been seen. Most adnexal cysts are presumed to arise from the ovary and are hence misdiagnosed both clinically and radiologically, and the definitive diagnosis of Müllerian duct cysts is made at the time of surgery. They may also be mistaken as paratubal, paraovarian or peritoneal inclusion cysts and hydrosalpinx. Paraovarian and paratubal cysts are usually found in the mesosalpinx between the ovary and fallopian tube. They may be unilocular or sometimes, multilocular, usually single, thin walled cysts and contain clear serous fluid of low specific gravity. On histopathology, their walls consist of varying quantities of fibro-collagenous tissue and smooth muscle cells along with congested blood vessels \& chronic inflammatory cells, and their epithelial linings may be simple cuboidal, columnar, or ciliated and pseudostratified. Specific immuno-staining is useful to make a definite diagnosis of Müllerian cyst of the uterus.

A Müllerian duct cyst of apparent uterine origin anatomically with healthy fallopian tubes has been very infrequently reported in the literature. Lui et al reported a 47-year-old woman with an incidental finding of a right adnexal mass on pelvic sonography, suspected to be an ovarian cyst for which laparoscopy was done wherein, a pedunculated cystic mass arising from the right anterior uterine wall was seen. ${ }^{4}$ The mass was resected laparoscopically and histologic examination showed a benign Müllerian cyst of the uterus. In another case reported by Nakae et al, a 45-year-old woman presented with pelvic cystic mass, which was initially diagnosed as a paraovarian cyst by ultrasound and magnetic resonance imaging. ${ }^{5}$ On laparoscopy, it proved to be a pedunculated uterine cyst which was resected and histology confirmed it to be a Müllerian cyst of the uterus. A similar case like ours has been reported by Datti et al where the patient 
was taken for exploratory laparotomy for a large ovarian cyst as the diagnosis, but the cyst was a paraovarian cyst; histopathology proved to be a mullerian duct cyst. ${ }^{6}$ Peralta et al reported three cases of benign retroperitoneal cysts of Müllerian type in peri-menopausal and postmenopausal women and all of them presented as pelvic masses. ${ }^{7}$ A Müllerian cyst of the mesentery was reported by Lee et al and Harpazand Gellman reported a urogenital mesenteric cyst with fallopian tube features. ${ }^{8,9}$ Gowri et al reported a case with Müllerian type cyst presenting as irregular vaginal bleeding in a perimenopausal woman. ${ }^{10}$ Rashmi et al reported an unusual case of a vaginal Müllerian cyst presenting as an enterocele and Montella described a large anterior vaginal wall cyst in a female which was originally diagnosed as a cystocele. $^{11,12}$

\section{CONCLUSIONS}

Preoperative diagnosis of Müllerian cyst of the uterus can be very difficult. However, with increased awareness of this rare condition, preoperative diagnosis should be possible by sonography. Laparoscopy is useful as a minimally invasive treatment to diagnose as well as resect the cyst at the same time. The importance of our case, and the other few reported ones is that they help us understand the pathology arising from the vestigial remnants. The aim of reporting this case, however, is not only to describe the pathology, but also to contribute to consider Müllerian duct cyst as a differential diagnosis in these cases so that minimally invasive procedures may suffice in their management instead of a more radical approach.

Written informed consent was obtained from the patient for publication of this case report and accompanying images.

\section{Funding: Not required}

Conflict of interest: None declared

Ethical approval: Not required

\section{REFERENCES}

1. Mullerian cysts; in Pathology by systems, 2008. Available at www.humpath.com. Accessed on 20.07.2015.

2. Toy H, Toy, Yazıcı F. Female Genital Tract Cysts. Eur J Gen Med. 2012;9(1):21-6.

3. Coppens L, Bonnet P, Andrianne R, de Leval J. Adult mullerian duct cyst. J Urol. 2002;167(4):17404.

4. Lui MW, Ngu SF, Cheung VY. Mullerian cyst of the uterus misdiagnosed as ovarian cyst on pelvic sonography. J Clin Ultrasound. 2014;42(3):183-4.

5. Nakae H, Osuga $Y$, Fujimoto A, Nakagawa S, Ichinose M, Yano T, et al. Müllerian cyst of the uterus treated with laparoscopy and diagnosed using immunohistology. J Obstet Gynaecol Res. 2013;39(1):430-3.

6. Datti Sujata N, Ray P, Jayashree AK, Shariff S. An unusual presentation of paraovarian cyst. J Clin Biomed Sci. 2013;3(4):196-8.

7. Peralta MN, Delahoussaye PM, Tornos CS, Silva EG. Benign retroperitoneal cysts of the Mullerian type: A clinicopathologic study of three cases and review of the literature. Int $\mathrm{J}$ Gynecol Pathol. 1994;13:273-8.

8. Lee J, Song SY, Park CS, Kim B. Mullerian cysts of the mesentery and retro peritoneum: A case report and literature. Pathol Int. 1998;48:902-6.

9. Harpaz N, Gellman E. Urogenital mesenteric cyst withFallopian tube features. Arch Pathol Lab Med. 1987;111:78-80.

10. Gowri V, Busaidi FA, Vadakkepat N, Kaur S. Benign mullerian type cyst of the uterus in a perimenopausal woman. Saudi Med J. 2003;24(12):1400-1.

11. Rashmi, Suneja A, Agarwal N, Guleria K, Yadav P. Vaginal mullerian cyst presenting as enterocele. J Obstet Gynecol. 2009;59:74-6.

12. Montella JM. Vaginal mullerian cyst presenting as a cystocele. Obstet Gynecol. 2005;105:1182-4.

Cite this article as: Singh A, Shree S, Mishra V, Radhakrishnan G. Müllerian duct cyst misdiagnosed as ovarian cyst: a rare case report. Int J Reprod Contracept Obstet Gynecol 2016;5:1260-2. 